\title{
Crystal and molecular structure of triphenylphosphine (N,N-diethyldithiocarbamato)gold(I)
}

\author{
J. G. Wunhoven, W. P. J. H. Bosman and P. T. Beurskens \\ Crystallography Laboratory, University of Nijmegen, Nijmegen, \\ The Netherlands
}

(Received 1 September 1971)

\begin{abstract}
The crystal and molecular structure of triphenylphosphine (N,N-diethyldithiocarbamato)gold(I), $\left(\mathrm{C}_{6} \mathrm{H}_{5}\right)_{3} \mathrm{PAuSSCN}\left(\mathrm{C}_{2} \mathrm{H}_{5}\right)_{2}$, has been determined by threedimensional X-ray methods. The compound crystallizes in the monoclinic space group $P 2_{1} / c$ with $a=13.547(1), b=12.277(1), c=14.013(1) \AA, \beta=90.81(1)^{\circ}$ and $Z=4$. Three-dimensional intensity data were collected on an automatic diffractometer. Atomic parameters were refined by full-matrix least-squares methods to a conventional $R$ value of 0.04 for 2318 non-zero observed reflexions.

In this complex the diethyldithiocarbamate moiety acts as a monodentate ligand, the $\mathrm{C}-\mathrm{S}$ double-bond distance being $1 \cdot 68(1) \AA$ and the $\mathrm{C}-\mathrm{S}$ bond involving the sulphur atom that is coordinated to the gold atom being 1.75(1) $\AA$. The gold atom is linearly coordinated, the S-Au-P angle being $175.7(1)^{\circ}$ and the $\mathrm{Au}-\mathrm{S}$ and $\mathrm{Au}-\mathrm{P}$ distances being 2.338(3) and 2.251(3) $\AA$, respectively.
\end{abstract}

\section{Introduction}

The present compound, $\left(\mathrm{Ph}_{3} \mathrm{P}\right) \mathrm{Au}$ (dtc), was prepared by Brinkhoff et al. (1971). The crystal structure analysis was undertaken to determine whether the gold atom is in three-fold coordination (with phosphine and bidentate dithiocarbamate) or in the usual two-fold coordination (with phosphine and monodentate dithiocarbamate moieties).

\section{Crystal data}

\section{Experimental}

Triphenylphosphine (N,N-diethyldithiocarbamato)gold(I), $\left(\mathrm{C}_{6} \mathrm{H}_{5}\right)_{3} \mathrm{PAuSSCN}$ $\left(\mathrm{C}_{2} \mathrm{H}_{3}\right)_{2}\left[=\left(\mathrm{Ph}_{3} \mathrm{P}\right) \mathrm{Au}(\mathrm{dtc})\right], F W=607 \cdot 5$. The well-formed yellow crystals are

Copyright (1 1972 Plenum Publiahing Company Limited. No part of this publication may be reproduced, etored in a retrieval system, or transmitted, in any form or by any means, electronic, mechanical, photo. copying, microfilming, recorcing or otherwise, without written permistion of Pleaum Publishimg Company Limited. 
elongated along $c$ with crystal forms $\{110\},\{100\}$ and $\{001\}$. The crystals are monoclinic, space group $P 2_{1} / c$ (No. 14) determined from systematic absences. From Pt-calibrated Weissenberg photographs around $b$ and $c$ using nickelfiltered $\mathrm{Cu} K \alpha$ radiation $(\lambda=1.5418 \AA)$, application of a least-squares procedure yielded the unit cell dimensions: $a=13.547(1), b=12 \cdot 277(1), c=14 \cdot 013(1) \AA$, $\beta=90.81(1)^{\circ} ; V_{c}=2330.4(5) \AA^{3}$. The calculated density of $1.73 \mathrm{~g} \mathrm{~cm}^{-3}$, with $Z=4$, agrees with the measured value of $1.73 \mathrm{~g} \mathrm{~cm}^{-3}$ (flotation method). $F(000)=$ 1184. The linear absorption coefficient for molybdenum $K \alpha$ radiation is $\mu=67.7$ $\mathrm{cm}^{-1}$.

\section{Intensity data}

A crystal of approximate dimensions $0.05 \times 0.05 \times 0.6 \mathrm{~mm}^{3}$ was mounted with $c$ along the $\phi$-axis of a Nonius automatic diffractometer. Intensity data were measured with $\mathrm{Zr}$-filtered Mo-radiation using the moving-counter moving-crystal method with a scan speed of $1.2 \%$ min. After every 20 reflexions a reference reflexion was measured to detect and allow corrections to be made for slow fluctuations in the primary beam. Of the $\mathbf{3 7 3 8}$ attainable symmetry independent reflexions $h k l$ (up to $\sin \theta / \lambda=0.59 \AA^{-1}$ ), 2193 reflexions have been measured above background. Of the 2015 attainable symmetry related reflexions $h k l$ (up to $\sin \theta / \lambda=0.48 \AA^{-1}$ ), 1588 reflexions have been measured above background. (A reflexion is considered 'above background' if its peak intensity exceeds an instrumentally fixed value set slightly above the average background.) Absorption corrections were calculated according to the Busing \& Levy (1957) procedure, using $6 \times 6 \times 4$ volume components and seven photographically located boundary planes (the absorption factors were in the range $1 \cdot 36-1 \cdot 41$ ). The two symmetryrelated sets of refiexions were brought on the same scale and corrected for $L p$ factors. The disagreement factor for reflexions common in both sets is:

$$
R^{\prime}=\Sigma^{\prime}|| F_{h k l}|-| F_{h k t}|| \Sigma_{\frac{1}{2}}\left[\left|F_{h k l}\right|+\left|F_{\text {hikl }}\right|\right]=0.041
$$

The variance of an observed structure amplitude was calculated as

$$
\sigma_{h k l}^{2}=\sigma_{c}^{2}+\left(\alpha^{\prime}\left|F_{n k l}\right|\right)^{2}
$$

where $\sigma_{c}$ is the standard deviation calculated from counting statistics, and $a^{\prime}$ is a constant, taken as 0.05 . For weak reflexions the statistical errors in counting predominate, and therefore eqn. (1) gives better estimations of the variances of the weak reflexions than may be obtained by some well-known formulas (e.g. Hughes, 1941 ; Cruickshank, 1961). For strong reflexions the standard deviation given by eqn. (1) will become proportional to the observed structure amplitude. The value used for $a^{\prime}$ reflects our assumption of a $5 \%$ error in large structure amplitudes.

Eqn. (1) has been used also by Killean (1969), but for simplicity we prefer not to interpret the physical meaning of $a^{\prime}$ and to guess its value. A generalization of eqn. (1), where $a^{\prime}$ is replaced by an intensity and scattering-angle dependent function determined from the deviations between symmetry-related intensities, has been published by Noordik (1971). 
For the reflexions common in the symmetry-related sets of measurements, the weighted average $|F|$ was calculated using weights obtained by eqn. (1). The variance $\sigma|F|^{2}$ of the mean structure amplitude was calculated as either

$$
\sigma^{2}|F|=\left[\sigma_{\text {hlil }}^{-2}\left(|F|-\left|F_{h k l}\right|\right)^{2}+\sigma_{h k l}^{-2}\left(|F|-\left|F_{h k l}\right|\right)^{2}\right] /\left[\sigma_{\text {hkl }}^{2}+\sigma_{h k l}^{-2}\right]
$$

or

$$
\sigma^{2}|F|=1 /\left[\sigma_{h k l}^{-2}+\sigma_{h k l}^{-2}\right]
$$

whichever was the larger.

\section{Structure determination}

The structure was solved by Patterson and Fourier methods; the positions of all atoms (except bydrogen) were located. The positional and vibrational parameters and the scale factor were refined by full-matrix least-squares methods, allowing anisotropic vibration of the gold, sulphur and phosphorus atoms. The function that was minimized was $\Sigma w\left(\left|F_{0}\right|-\left|F_{c}\right|\right)^{2}$, with weight $w=\sigma^{-2}$ for each reflexion as obtained from eqn. (1) or (2). The atomic scattering factors were corrected for the anomalous scattering component $\Delta f^{\prime}$ using data from the International Tables (1962). A conventional $R$ value of 0.044 was obtained. The positions of the hydrogen atoms attached to the benzene rings and to $C(2)$ and $C(4)$ were calculated and included in the structure factor calculations with isotropic temperature factors equal to the temperature factors of the 'parent' carbon atoms. Two more least-squares refinement cycles reduced the conventional $R$ value to 0.040 for 2318 non-zero observed reflexions. The parameter changes in the last cycle were only a small fraction of the standard deviations. A final difference Fourier synthesis showed some peaks of $0.5 \mathrm{eA}^{-9}$ on the expected positions of the hydrogen atoms attached to $C(3)$ and $C(5)$ but some other equally high peaks as well, so we did not include these hydrogen atoms in the structure factor calculations.

Calculations were performed on an IBM 360/50 computer using programs written by Busing et al. (1962), Johnson (1965), and Ahmed \& Pippy (1968), and several programs written at this laboratory.

\section{Results and discussion}

The atomic parameters are given in tables 1 and 2 . The structure is illustrated in figure 1 , bond distances and angles are given in figure 2 and table 3 .

The gold atom is in linear coordination, as usual for $\mathbf{A u}(\mathrm{I})$, the $\mathrm{S}(1)-\mathbf{A u}-\mathbf{P}$ angle being $175 \cdot 7(1)^{\circ}$. The $\mathrm{Au}-\mathrm{S}(1)$ and $\mathrm{Au}-\mathrm{P}$ bond lengths are $2 \cdot 338(3)$ and $2 \cdot 251(3) \AA$, respectively. The deviation from strict linearity $\left(4 \cdot 3^{\circ}\right.$, visible in figure 2) may be explained easily by the influence of the sulphur atom $S(2)$; the Au-..S(2) distance of 3.015(3) $\AA$ is somewhat less than the expected van der Waals distance (the sum of Pauling's van der Waals radius of $S$ and the single-bond metallic radius of $\mathrm{Au}$ is $3 \cdot 19 \AA$ ).

In contrast to its behaviour in many other structures, the dithiocarbamate 
Table 1. Atomic parameters for $\left(\mathrm{Ph}_{3} \mathrm{P}\right) \mathrm{Au}(\mathrm{dtc})$ with standard deviations

(a) $\mathrm{Au}, \mathrm{S}$ and $\mathrm{P}$ atoms with anisotropic temperature factors:

\begin{tabular}{|c|c|c|c|c|c|c|c|c|c|}
\hline \multicolumn{10}{|c|}{$\exp \left(\beta_{11} h^{2}+\beta_{22} k^{2}+\beta_{33} l^{2}+2 \beta_{12} h k+2 \beta_{13} h l+2 \beta_{23} k l\right)^{*}$} \\
\hline & $\therefore x$ & $y$ & 2 & $10^{4} \beta_{11}$ & $10^{4} \beta_{22}$ & $10^{4} \beta_{33}$ & $10^{4} \beta_{12}$ & $10^{4} \beta_{13}$ & $10^{4} \beta_{23}$ \\
\hline $\begin{array}{l}\mathrm{Au} \\
S(1) \\
S(2) \\
\mathbf{P}\end{array}$ & $\begin{array}{l}0.31576(3) \\
0.3029(2) \\
0.1351(2) \\
0.3364(2)\end{array}$ & $\begin{array}{c}0.07432(4) \\
-0.0453(2) \\
-0.0690(3) \\
0.1968(2)\end{array}$ & $\begin{array}{l}0.28038(3) \\
0.1509(2) \\
0.2833(2) \\
0.3986(2)\end{array}$ & $\begin{array}{l}55 \cdot 7(3) \\
56(2) \\
72(2) \\
53(2)\end{array}$ & $\begin{array}{c}64 \cdot 3(4) \\
85(3) \\
133(4) \\
67(2)\end{array}$ & $\begin{array}{l}45 \cdot 2(3) \\
58(2) \\
53(2) \\
47(2)\end{array}$ & $\begin{array}{c}-4 \cdot 6(3) \\
-8(2) \\
-38(2) \\
-7(2)\end{array}$ & $\begin{array}{c}-4 \cdot 4(2) \\
6(2) \\
11(2) \\
-1(1)\end{array}$ & $\begin{array}{c}-10 \cdot 3(3) \\
-18(2) \\
-25(2) \\
-8(2)\end{array}$ \\
\hline
\end{tabular}

(b) $\mathbf{N}$ and $\mathbf{C}$ atoms with isotropic temperature factor parameters $\mathbf{B}\left(\AA^{2}\right)$

\begin{tabular}{|c|c|c|c|c|c|c|c|c|c|}
\hline 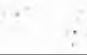 & $\boldsymbol{x}$ & $y$ & $z$ & $B$ & & $x$ & $y$ & $z$ & $\boldsymbol{B}$ \\
\hline $\mathbf{N}$ & $0.1376(6)$ & $-0.1531(7)$ & $0 \cdot 1099(6)$ & $4 \cdot 4(2)$ & $C(12)$ & $0 \cdot 233(1)$ & $0.203(1)$ & $0.481(1)$ & $3 \cdot 8(2)$ \\
\hline$C(1)$ & $0.1852(7)$ & $-0.0951(8)$ & $0.1764(7)$ & $3 \cdot 6(2)$ & C(13) & $0.215(1)$ & $0.296(1)$ & $0.533(1)$ & $4 \cdot 2(2)$ \\
\hline$C(2)$ & $0 \cdot 177(1)$ & $-0.170(1)$ & $0.012(1)$ & $6 \cdot 8(3)$ & C(14) & $0 \cdot 138(1)$ & $0.298(1)$ & $0.598(1)$ & $4 \cdot 8(2)$ \\
\hline$C(3)$ & $0.132(1)$ & $-0.089(1)$ & $-0.053(1)$ & $8 \cdot 8(4)$ & $C(15)$ & $0.080(1)$ & $0.205(1)$ & $0.609(1)$ & $4 \cdot 4(2)$ \\
\hline C(4) & $0.039(1)$ & $-0.201(1)$ & $0.128(1)$ & $5-5(3)$ & $C(16)$ & $0.098(1)$ & $0 \cdot 115(1)$ & $0.559(1)$ & $4 \cdot 6(2)$ \\
\hline$C(5)$ & $0-049(1)$ & $-0.313(1)$ & $0.167(1)$ & $8 \cdot 1(4)$ & C(17) & $0.174(1)$ & $0.110(1)$ & $0.491(1)$ & $4 \cdot 4(2)$ \\
\hline$C(6)$ & $0 \cdot 347(1)$ & $0.336(1)$ & $0.356(1)$ & $4 \cdot 2(2)$ & $C(18)$ & $0.444(1)$ & $0.174(1)$ & $0.472(1)$ & $3 \cdot 7(2)$ \\
\hline $\mathrm{c}(7)$ & $0.281(1)$ & $0.371(1)$ & $0.286(1)$ & $5 \cdot 2(3)$ & $c(19)$ & $0.446(1)$ & $0.194(1)$ & $0.572(1)$ & $5 \cdot 4(3)$ \\
\hline$C(8)$ & $0 \cdot 284(1)$ & $0.477(1)$ & $0.253(1)$ & $6 \cdot 2(3)$ & $C(20)$ & $0.534(1)$ & $0 \cdot 178(1)$ & $0.626(1)$ & $5 \cdot 7(3)$ \\
\hline C(9) & $0.353(1)$ & $0.549(1)$ & $0.292(1)$ & $6.1(3)$ & $C(21)$ & $0.615(1)$ & $0 \cdot 146(1)$ & $0.582(1)$ & $5 \cdot 6(3)$ \\
\hline C(10) & $0.420(1)$ & $0.518(1)$ & $0.357(1)$ & $6 \cdot 6(3)$ & $C(22)$ & $0 \cdot 617(1)$ & $0 \cdot 125(1)$ & $0.487(1)$ & $7 \cdot 3(3)$ \\
\hline C(11) & $0.418(1)$ & $0.409(1)$ & $0.391(1)$ & $5 \cdot 6(3)$ & $C(23)$ & $0.528(1)$ & $0 \cdot 137(1)$ & $0.430(1)$ & $5 \cdot 7(3)$ \\
\hline
\end{tabular}

- The anisotropic vibration parameters correspond to an average r.m.s. displacement of $0.22 \AA$, except for the atom $S(2)$, having a r.m.s. displacement of $0.36 \AA$ about normal to the plane of the (dtc) ligand.

The key to atomic numbering is given in figure 2 . The hydrogen positions are given in table 2. 
STRUCTURE OF $\left(\mathrm{C}_{6} \mathrm{H}_{5}\right)_{3}$ PAUSSCN $\left(\mathrm{C}_{2} \mathrm{H}_{5}\right)_{2}$

Table 2. Calculated positions of the hydrogen atoms

\begin{tabular}{|c|c|c|c|c|c|c|c|}
\hline & $x$ & $y$ & $z$ & & $x$ & $y$ & $z$ \\
\hline$H(2 a)$ & 0.163 & -0.252 & -0.014 & $H(10)$ & 0.472 & 0.578 & 0.390 \\
\hline$H(2 b)$ & 0.260 & -0.158 & 0.009 & $H(11)$ & 0.478 & 0.382 & 0.438 \\
\hline $\mathrm{H}(3 \mathrm{a})^{*}$ & 0.052 & -0.090 & -0.041 & H(13) & 0.267 & $0 \cdot 370$ & 0.518 \\
\hline$H(3 b)^{*}$ & $0 \cdot 147$ & -0.110 & -0.126 & $H(14)$ & 0.128 & 0.371 & 0.644 \\
\hline$H(3 c)^{*}$ & $0 \cdot 160$ & -0.008 & -0.037 & $H(15)$ & 0.017 & 0.215 & 0.656 \\
\hline$H(4 a)$ & -0.003 & -0.204 & 0.064 & $\mathbf{H}(16)$ & 0.058 & 0.037 & 0.573 \\
\hline $\mathrm{H}(4 \mathrm{~b})$ & 0.001 & -0.149 & 0.181 & H(17) & 0.197 & 0.038 & 0.449 \\
\hline $\mathrm{H}(5 \mathrm{a})^{*}$ & -0.023 & -0.345 & $0 \cdot 185$ & H(19) & 0.388 & 0.242 & 0.601 \\
\hline $\mathbf{H}(5 b)^{*}$ & 0.095 & -0.311 & 0.232 & H(20) & 0.526 & 0.186 & 0.707 \\
\hline$H(5 c)^{*}$ & 0.083 & -0.365 & 0.114 & $\mathbf{H}(21)$ & 0.689 & 0.153 & 0.619 \\
\hline $\mathrm{H}(7)$ & 0.226 & 0.311 & 0.266 & $\mathrm{H}(22)$ & 0.684 & 0.081 & 0.460 \\
\hline$H(8)$ & 0.230 & 0.505 & 0.194 & $\mathbf{H}(23)$ & 0.534 & 0.131 & 0.354 \\
\hline $\mathbf{H}(9)$ & 0.351 & 0.633 & 0.265 & & & & \\
\hline
\end{tabular}

Atoms not included in the structure factor calculations are indicated by asterisks. The numbers of the atoms refer to the parent carbon atoms.

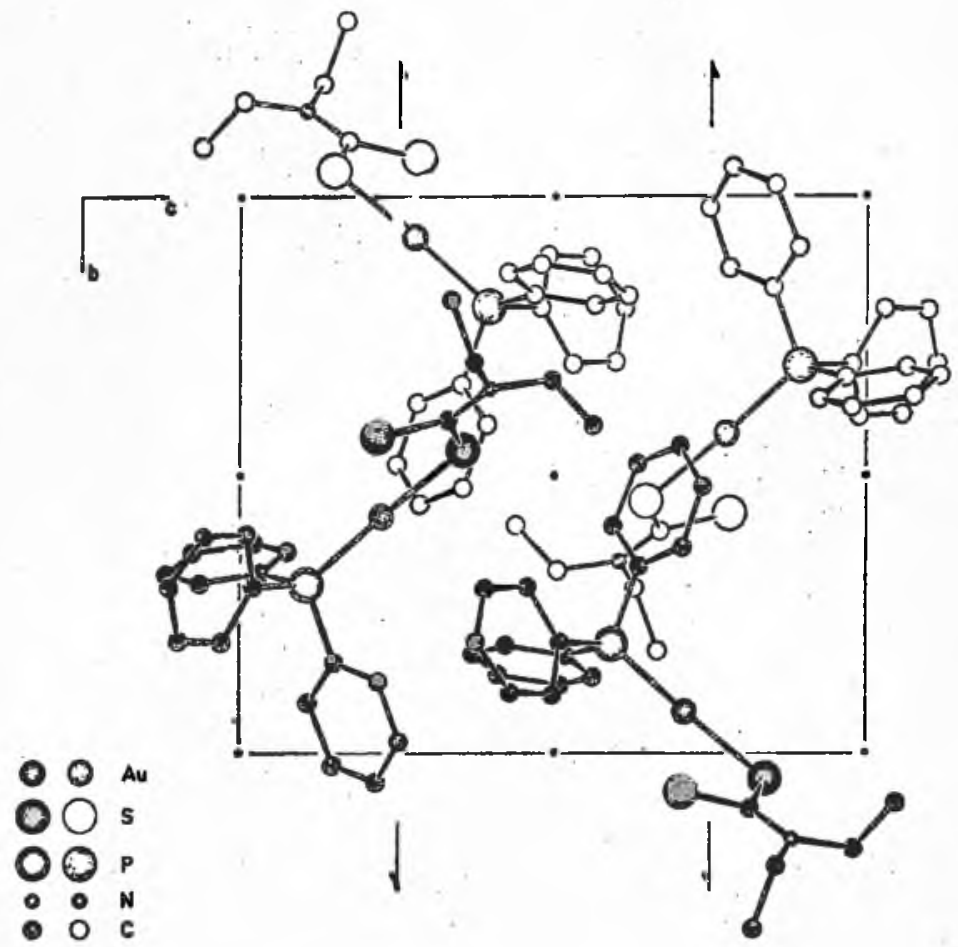

Fig. 1. Projection of the structure of $\mathrm{Ph}_{3} \mathrm{PAu}$ (dtc) along a. Centres of symmesry and two-fold screw ares are indicated. 


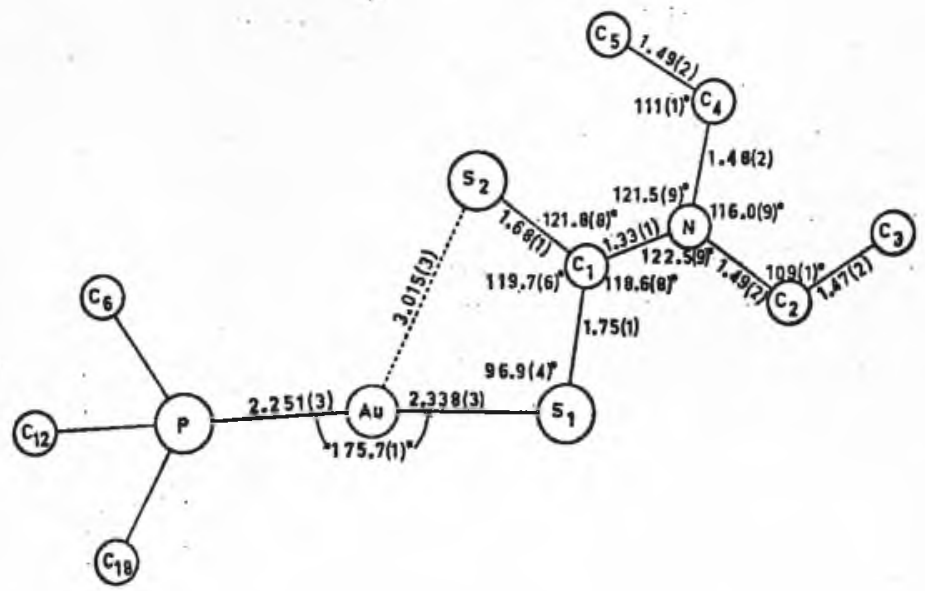

Fig. 2. Dimensions of the (dtc)-ligand and the coordination of the gold atom. Dimensions of the $\mathrm{Ph}_{3} \mathrm{P}$-ligand are given in table 3.

group acts as a monodentate ligand, $S(1)$ being bonded to the gold atom, while the $\mathrm{S}(2) \cdots A$ u distance is as much as 3-015 $\AA$. Relative to the normal situation, where the two $\mathrm{C}-\mathrm{S}$ bonds have partial double bond character, the present situation may be represented by a weakening of the $C(1)-S(1)$ bond and the formation of a $\mathrm{C}(1)-\mathrm{S}(2)$ double bond. This is shown by the highly significant difference in the bond lengths $C(1)-S(1), 1 \cdot 75(1) \AA$ and $C(1)-S(2), 1.68(1) \AA$, whereas the average $C-S$ bond for dithiocarbamato-gold complexes is $1.71 \AA$ (Noordik \& Beurskens, 1971). In table 4, some distances found in asymmetrically bonded dithiocarbamates are given.

The equation of the least-squares plane through $S(1), S(2), C(1)$ and $N$ is given by

$$
-0.4027 X+0.8384 Y-0.3672 Z+2.8827=0
$$

referred to an orthogonal axes system with $X$ along $a$ and $Z$ along $c^{*}$; the deviations from this plane are for $\mathrm{C}(2), 0 \cdot 11(1)$ and for $\mathrm{C}(4),-0.05(1) \AA$. The $\mathrm{Au}$ atom is about $0.5 \AA$ out of this plane, which again is in contrast to most dithiocarbamato complexes.

The $\mathrm{Au}-\mathrm{S}(1)$ distance, $2 \cdot 338(3) \AA$, agrees very well with the average Au-S distance of $2 \cdot 333 \AA$ found in other dithiocarbamato-gold complexes (Noordik \& Beurskens, 1971).

The triphenylphosphine ligand is in the usual trigonal-pyramidal configuration. The best planes through the three benzene rings are given as follows:

$$
\begin{aligned}
& \text { plane 1: } C(6)-C(11): \quad 0.6447 X-0.2709 Y-0.7148 Z+1.6870=0 \\
& \text { plane 2: } C(12)-C(17):-0.6151 X+0.3261 Y-0.7179 Z+5.9037=0 \\
& \text { plane 3: } C(18)-C(28): 0.2597 X+0.9495 Y-0.1759 Z-2.3939=0
\end{aligned}
$$


Table 3. Bond distances and angles in the $\left(\mathrm{Ph}_{3} \mathrm{P}\right)$ ligand with standard deviations




Table 4. Some distances in asymmetrically bonded dithiocarbamato complexes. ( $\AA$ )

\begin{tabular}{|c|c|c|c|c|c|c|}
\hline$M$ & $M-\mathrm{S}(1)$ & $M-S(2)$ & $S(1)-C$ & $S(2)-C$ & Compound & Note \\
\hline $\mathbf{A u}$ & $2 \cdot 324(5)$ & $2 \cdot 329(5)$ & $1 \cdot 73(2)$ & $1 \cdot 69(2)$ & $\mathrm{Au}(\mathrm{dtc})\left(\mathbf{S}_{2} \mathrm{C}_{4} \mathbf{N}_{2}\right)$ & 1 \\
\hline Sn & $2 \cdot 48(1)$ & $2 \cdot 79(1)$ & $1 \cdot 68(4)$ & $1 \cdot 74(4)$ & $\left(\mathrm{CH}_{3}\right)_{2} \mathrm{ClSn}(\mathrm{dtc})$ & 2 \\
\hline $\mathrm{Te}$ & $2 \cdot 498(7)$ & $2 \cdot 856(8)$ & $1 \cdot 76(3)$ & $1 \cdot 69(2)$ & $\mathrm{Te}(\mathrm{dtc})_{2}$ & 3 \\
\hline Se & $2 \cdot 332(4)$ & $2 \cdot 779(5)$ & $1 \cdot 75(2)$ & $1 \cdot 65(2)$ & $\mathrm{Se}(\mathrm{dtc})_{2}$ & 4 \\
\hline As & $2 \cdot 322(6)$ & $2 \cdot 835(6)$ & $1 \cdot 76(2)$ & $1.69(2)\}$ & $\mathrm{C}_{6} \mathrm{H}_{5} \mathrm{As}$ (dtc) & 5 \\
\hline As & $\begin{array}{l}2 \cdot 330(6) \\
2 \cdot 351(3)\end{array}$ & $\begin{array}{l}2 \cdot 911(6) \\
2 \cdot 903(4)\}\end{array}$ & $1 \cdot 78(2)$ & $1 \cdot 65(2)\}$ & & \\
\hline & $\begin{array}{l}2 \cdot 336(2) \\
2 \cdot 358(3)\end{array}$ & $\left.\begin{array}{l}2 \cdot 820(3) \\
2 \cdot 810(3)\end{array}\right\}$ & $1 \cdot 76(1)$ & $1 \cdot 68(1)$ & $A s(d t c)_{3}$ & 6 \\
\hline Sn & $\begin{array}{l}2 \cdot 47(1) \\
2 \cdot 47(1)\end{array}$ & $\begin{array}{l}3 \cdot 16(1) \\
3 \cdot 33(1)\end{array}$ & $\begin{array}{l}1 \cdot 80(2) \\
1 \cdot 78(3)\end{array}$ & $\begin{array}{l}1 \cdot 70(3)\} \\
1 \cdot 71(3)\end{array}$ & $\left(\mathrm{CH}_{3}\right)_{3} \mathrm{Sn}(\mathrm{dtc})$ & 7 \\
\hline $\mathbf{A u}$ & $\begin{array}{l}2 \cdot 338(3) \\
2 \cdot 398\end{array}$ & $\begin{array}{l}3.015(3) \\
3.633\end{array}$ & $1.75(1)$ & $1 \cdot 68(1)$ & $\begin{array}{l}\mathrm{Ph}_{3} \mathrm{PAu}(\mathrm{dtc}) \\
\mathrm{Ru} \text { (NO)(dtc) }\end{array}$ & $\begin{array}{l}8 \\
9\end{array}$ \\
\hline- & & & & $1 \cdot 63$ & $\mathbf{R}_{4} N_{2} \mathrm{C}_{2} \mathrm{~S}_{4}$ & 10 \\
\hline
\end{tabular}

Notes: (dtc) $=\mathrm{S}_{2} \mathrm{CNR}_{2}$ with $\mathrm{R}=\mathrm{CH}_{3}, \mathrm{C}_{2} \mathrm{H}_{5}, \mathrm{C}_{4} \mathrm{H}_{9}$ or $\frac{1}{2}\left(\mathrm{OC}_{4} \mathrm{H}_{8}\right)$.

(1) The slight asymmetry of the (dtc) ligand is caused by interactions from a neighbouring molecule (Noordik, 1971).

(2) The difference in S-C distances, albeit non-significant, is in contrast to other entries in this table (Furue et al., 1970).

(3) Husebye, 1970.

(4) Husebye \& Helland-Madsen, 1970.

(5) Bally, 1967.

(6) The given $S-C$ distances are averaged (Colapietro et al., 1968).

(7) The given distances apply to two crystallographically independent molecules (Sheldrick \& Sheldrick, 1970).

(8) This work.

(9) The given distances apply to the one monodentate (dtc) ligand; $\mathrm{S}-\mathrm{C}$ distances were not reported (Domenicano et al., 1966).

(10) Average $\mathrm{S}=\mathrm{C}$ distance in $\left(\mathrm{CH}_{3}\right)_{4} \mathrm{~N}_{2} \mathrm{~S}_{2} \mathrm{C}_{4}(1.61 \AA)(\mathrm{Mar} ø \mathrm{y}, 1965)$, and in $\left(\mathrm{C}_{2} \mathrm{H}_{5}\right)_{4} \mathrm{~N}_{2} \mathrm{~S}_{2} \mathrm{C}_{4}(1.63$ and $1.66 \AA$ ) (Karle et al., 1967).

The angles between the planes 1 and 2,2 and 3 and 3 and 1 are $88^{\circ} 23^{\prime}, 73^{\circ} 58^{\prime}$ and $87^{\circ} 57^{\prime}$, respectively. Bond angles and distances within the ligand agree with those found in other triphenylphosphine derivatives.

Despite the irregular shape of the molecule, there exists a reasonably close packing in the crystal. The packing coefficient was calculated to be 0.689 . For triphenylmethane, it is 0.638 ; other polyphenyls range from 0.685 to 0.746 (Kitaigorodskii, 1961). There are no unusual intermolecular interactions. The shortest intermolecular distance is $\mathrm{Au} \cdots \mathrm{C}(21)=3.44 \pm 0.01 \AA$.

\section{Acknowledgements}

The authors are grateful to Professor J. J. Steggerda for his continuous interest and to Mr J. M. M. Smits for valuable assistance. 


\section{References}

Ahmed, F. R. \& Pippy, M. E. (1968) Crystallographic computer programmes (NRC. $3,8,12,22)$. World list of Crystallographic Computer Programs 2nd ed. Appendix, p. 52. Bally, R. (1967) Acta Crystallogr. 23, 295.

Brinkhoff, H. C., Matthijssen, A. G. \& Oomes, C. G. (1971) Inorg. Nucl. Chem. Letters 7. 87.

Busing, W. R. \& Levy, H. A. (1957) Acta Crystallogr. 10, 180.

Busing, W. R., Martin, K. O. \& Levy, H. A. (1962) Fortran least-squares program ORFLS). Oak Ridge National Laboratory Report 305.

Colapietro, M., Domenicano, A., Scaramuzza, L. \& Vaciago, A., (1968) Chem. Comm. 4, 302.

Cruickshank, D. W. J. (1961) X-ray Crystal Analysis (Pergamon Press) p. 45.

Domenicano, A., Vaciago, A. \& Zambonelli, L. (1966) Chem. Comm. 2, 476.

Furue, K., Kimura, T., Yasuoka, N., Kasai, N. \& Kakado, M. (1970) Bull. Chem. Soc. Jap. 43, 1661 ,

Hughes, E. W. (1941) J. Amer. Chem. Soc. 63, 1737.

Husebye, S. (1970) Acta Chem. Scand. $24,2198$.

Husebye, S. \& Helland-Madsen, G. (1970) Acta. Chem Scand. 24, 2273.

Johnson, C. K. (1965) Fortran thermal-ellipsoid plot program (ORTEP). Oak Ridge National Laboratory Report 3794.

Karle, I. L., Estlin, J. A. \& Britts, K. (1967) Acta Crystallogr. 22, 273.

Killean, A. C. (1969) Acta Crystallogr. B25, 374.

Kitaigorodskii, A. I. (1961) Organic Chemical Crystallography (Consultants Bureau, New York, p. 107).

Marøy, K. (1965) Acta Chem. Scand. 19, 1509.

Noordik, J. H. (1971) Ph.D. Thesis, Nijmegen.

Noordik, J. H. \& Beurskens, P. T. (1971) J. Cryst. Mol. Struct. 1, 339, and references therein.

Sheldrick, G. M. \& Scheldrick, W. S. (1970) J. Chem. Soc. (A), 490.

National Lending Library Supplementary Publication No. 60040 contains 12 pages of structure factor tables on 1 microfiche. 